\title{
Modeling Network-Based Defence: Success and Failure of an Enterprise Modeling Endeavour
}

\author{
Thomas Albertsen $^{1}$, Kurt Sandkuhl ${ }^{1,2}$, Ulf Seigerroth ${ }^{1}$, and Vladimir Tarasov ${ }^{1}$ \\ ${ }^{1}$ School of Engineering at Jönköping University, \\ P.O. Box 1026, 55111 Jönköping, Sweden \\ ${ }^{2}$ Rostock University, Institute of Computer Science, 18055 Rostock, Germany \\ \{Thomas.Albertsen, Kurt.Sandkuhl, Vladimir. Tarasov, \\ Ulf.Seigerroth\} ajth.hj.se
}

\begin{abstract}
Research projects have an inherent risk of failure, and learning how to cope with the risk is an important task for everyone involved. In order to do so it is necessary to share the knowledge of the experiences done during and after the project. This paper investigates a recently completed enterprise modeling research project and contributes with lessons learned and recommendations for future enterprise modeling projects.
\end{abstract}

Keywords: Enterprise Modeling, Competence Modeling, Experience report.

\section{Introduction}

In the last five years, the practices of enterprise modeling received more and more attention, which includes the use and development of methods, application of specific notations, combination of approaches from different modeling disciplines, participatory modeling approaches, and many more aspects (see [1] and [2] for an overview). In this context, lessons learned from problematic or failed enterprise modeling projects can be considered a contribution to the body of knowledge in the field.

The purpose of this paper is to investigate an enterprise modeling project recently completed in order to understand reasons for problems experienced in the project and potential strategies to avoid them. Many challenges occurring are well known as risks in project management. Lessons learned in this context are why the contingency plans did work. Other challenges originated from the type of the project and knowledge about them might be valuable fur future projects in this area. The contributions of this paper are experiences and lessons learned from an enterprise modeling case.

The paper is structured as follows. Section 2 introduces the background for this work including the enterprise modeling method and tools used. Section 3 describes the project and case in much detail, which originates from network-based defence. Section 4 discusses lessons learned from the project and derives recommendation for future projects. Section 5 summarizes the work and gives and outlook to future activities. 


\section{Background to Enterprise Modeling}

'Modeling' refers to a systematic set of actions taken in order "to describe a set of abstract or concrete phenomena in a structured and, eventually, in a formal way. Describing, modeling, and models is a key technique to support human understanding, reasoning, and communication" [1]. Modeling can be used in various domains like mathematics, geology, economics, climate, etc. When applied to enterprise - an organization created for business ventures [6] - it is called Enterprise Modeling (EM) which describes enterprise objectives, activities, information resources, processes, actors, products, requirements, and the like as well as relationships between those entities [2].

The outcomes of Enterprise modeling activity are enterprise models. They are the "representations of the pertinent aspects of an organization's structure and operation" [7]. Presley [7] also define enterprise model as "a symbolic representation of the enterprise and the things that it deals with. It contains representations of individual facts, objects, and relationships that occur within the enterprise" Enterprise models can be both descriptive and definitional with the aim of achieving model-driven enterprise design, analysis, and operation. "From a design perspective, an enterprise model should provide the language used to explicitly define an enterprise. From an operations perspective, the enterprise model must be able to represent what is planned, what might happen, and what has happened. It must supply the information and knowledge necessary to support the operations of the enterprise, whether they are performed by hand or machine. It must be able to provide answers to questions commonly asked in the performance of tasks" [2].

\section{Use and advantages}

Once the enterprise models have been created, they can have a variety of usages as well as many benefits for the company.

According to an earlier study made by [7], some examples among many uses of enterprise models are:

- Insight: by abstracting away the complexity of the overall organization, enterprise models can help to improve the understanding and the organization's workings.

- Communication: they can allow all members of the organization to see views of the enterprise based on a common picture.

- Enactment: they can be of great worth in designing and implementing the organization's processes.

Other examples of the use of enterprise models mentioned by [3]:

- Changes of organizational structure: to better suit to relevant business activities.

- Help for management: to gain complete view of the business organization.

- Business process reengineering: in the meaning of efficiency, etc.

As mentioned before, enterprise modeling can have many advantages for each employee in the company and for the entire organization.

Bubenko et al. [1] assert that one of the advantages of enterprise modeling is the effect on the participants. While modeling, the participants can get better 
understanding about the organization, its main goals, the different processes, how the processes are performed... The participants can also improve their capability to find solutions to problems in a participative way and by consensus of all the participants. Therefore, enterprise modeling enhances communication between the actors and it facilitates the process of organizational learning.

Another advantage of using EM is that it could help to convey semantic unification. It may happen that people in the company use different terms to express the same thing or they can use the same term to express things that are completely different. Enterprise modeling will offer a mutually agreed language to the different actors.

\section{The Network-Based Defence Case}

\subsection{Project Background}

Over the last decade the Swedish military has changed from a stable organization with the clear task of defending the Swedish borders, to a much smaller organization with diverse tasks including providing a combat ready taskforce organized under European command, the Nordic Battle Group (NBG). This task force can be deployed within a $600 \mathrm{~km}$ radius from Brussels on peace keeping missions. The military has also incorporated the network based defence paradigm where all units should concurrently provide data to support a complete view of the situation.

To support competence supply for this leaner organization, the KoMo-project was initiated as cooperation between the Swedish military and the School of Engineering (JTH) of Jönköping University. The project started in May 2006 and had a runtime until the end of 2009. It was financed by the Swedish military and had the purpose of supporting competence supply within the Swedish armed forces by "developing methods, concepts and techniques for structuring, modeling and matching of competences on individual and organizational level". The need for this has become evident within the Swedish military organization since the focus of the military changed rapidly over the last years.

The organisation of the project changed over the time. From the beginning the project had two project owners, the human resource department FörbePers, and the research and development department for human resource information systems LedSystP. At the start-up of the project LedsystP was the main project owner and receiver of the results. However, the organisation of the Swedish military is dynamic and this department was eliminated during reorganisation after two years. The personnel involved in LedSysP was transferred to other departments and the responsibility for the project was moved to FörbePers.

\subsection{Project Phases}

The project can be divided into two major phases. The first year was focused on quality assurance of an information system under development. The last two years of the project had the purpose of creating concepts and methods for modeling competence demand within the organization. 
The evaluated information system was created to support competence supply within the military and also to give future guidelines for development of information systems within the military. This quality assurance had two goals: to make sure that the system was fulfilling the given requirements and to illuminate the present Stateof-the-Art within the research community to support the development of the system.

The modeling part of the project had a wide focus in the beginning since there were no clear requirements from the military regarding what the exact purpose of the research should be. The focus was adjusted with the project development. The first intentions were to focus on individual competence and relations between individuals to support formation of teams, but this approach was not well received by some of the stakeholders from the military side. The second approach was to formulate a method for expressing competence demand using enterprise models. This was done using domain experts from the military.

The competence demand approach was to model a part of the NBG from the top of the organization down to a single unit. This was done stepwise starting from the top. The overall organisation in which NBG resides was modelled with a domain expert from the Swedish Army strategic planning department. From JTH two modeling experts where present to facilitate the modeling.

The second step of this approach was to model a unit in the NBG. The purpose of this modeling was to capture the unit's organisation and processes to express competence demand. The unit in question was the an airborne infantry unit and the domain expert was the Commanding officer. The modeling was done by two modeling experts from JTH using interview guidelines to support the modeling process.

After the modeling session the models where created in the software Troux Architect using the Metis Framework.

The results of the two major phases of the project where delivered in several work packages. The first phase produced two separate reports which were well received by LedSysP. The second phase of the project resulted in one big final report which was presented to the stakeholders from FörbePers and the project was finalized.

\subsection{Success or Failure?}

When evaluating the project results regarding "success or failure?", different perspectives are possible: customer and researcher.

The customer expressed satisfaction with the project results, stated that most of the original goals were reached and that the overall evaluation was positive. The project contributed to the quality assurance of the competence matching platform developed in the first project phase, new ideas and concepts for competence modeling and supply were provided to the military organisation, the competence models developed delivered a proof concept for the new ideas, and all deliverables were provided in time and good quality. However, the basis for this judgement on the customer side is an "adjusted" ambition level in the sense that the customer is aware of the own deficits during the project and accepts that some of the individual goals were not reached since the human resources were not available on customer side.

From a researcher's perspective, the project somehow seems to be unfinished, since the collected data motivating the work could not be validated and the new concepts developed had to be applied in a separate case, which was initiated for this 
purpose and taken from the own university. Furthermore, the project finished with substantial delay and exceeded the planned budget significantly. All in all, this constitutes a mixture of success and failure.

\section{Case Analysis and Lessons Learned}

\subsection{Typical Project Risks and Unsuitable Contingency Plans}

This section will summarize and discuss problems experienced in the project, which basically are a consequence of well-known project risks addressed in the contingency plans, but which still could not be fully avoided. The discussion of these problems will focus on the reasons why the contingency plans were not successful.

\section{Key personnel not available}

A typical risk for $R \& D$ projects with a runtime of several years is that key personnel might not be available at the required point in time or that they leave the project before it is completed. In the NBD project, this risk became reality on both customer and academic side. At Jönköping University, the $\mathrm{PhD}$ candidate who was supposed to be a main player in the project was sick during longer periods of the project, which created a challenge regarding the planning of research work: on the one hand, the NBD project was supposed to be the main source of empirical data for the $\mathrm{PhD}$ student and the context for validating new concepts. To deliver the project results without the $\mathrm{PhD}$ student would have been feasible, but would have created problems for the schedule of the overall $\mathrm{PhD}$ project. We managed to tackle this challenge by shifting the dates for deliverables to a later point in time and by involving additional researchers for certain parts of the project.

At the customer side, the selected colonel with experience in team formation for peace keeping missions was assigned to a task force in Afghanistan. This happened at a point in time, when the main part of the data collection already was completed and only clarifications and additional details were needed. However, the details turned out to be much more complex and important than originally expected. The contingency action was to perform the additional interviews with the colonel by using a wellestablished video link between Sweden and Afghanistan. After some severe military incidents in Afghanistan, this turned out to be not feasible. When returning from his mission, the project partner on the military side wasn't able to locate the colonel in question in Sweden. When located again, he was on another peace keeping mission, which was completed long after the project's end. Thus, the project had to accept the incomplete empirical data and create a second case.

Our conclusion from this endeavour is simple and consistent with project management recommendations: it is crucial with involvement of at least two domain experts (in our case the colonel with NBD experience) for project-critical subjects.

\section{Organisational changes}

Many project management handbooks point out that changes in the customer's organisation structure constitute a project risk, since the support for the project might be affected, and changes in business objectives might be an additional risk. From the 
very beginning, the NBD project had two project owners in the military organization sharing the funding and the responsibility (see also section 3). One of these owners was a development project, i.e. it was known that this project would finish some months before the end of the NBD project, the other one an organisation unit. Thus, all steering board and follow-up meetings of the project made sure that always both partners would be involved in order to avoid problems of the shared ownership. However, it turned out that the project owner had a more clearly defined interest in the results of the NBD project and that the organisation unit was keen to learn about new competence modeling opportunities, but did not have so precise objectives. The concrete problem showing when the institutional owner took over was that personnel resources had been allocated to the project, but the individuals supposed to work in the project had not been identified and informed. A new staffing phase began on the customer side, which required time and caused delays.

Our recommendation from this experience: if several project owners are involved, make sure that in addition to the overall (joint) project objectives also owner-specific objectives exist that are clearly expressed. Furthermore, explicitly plan the hand-over process from one owner to the next in the project plan.

\section{Shift in scope}

Many R\&D projects experience during their runtime a "scope creep", which often is originated by the knowledge gathered in the project and the necessity to adapt the project plan and the objectives to the new knowledge level. Such an adaptation often is positive for the project as such, since it indicates progress in the actual R\&D area, which is welcomed by both customer and developer. However, the challenges caused by such situations with respect to staffing of the project, agreement on changed objectives and preparation of new time plans are comparable with establishing a new project. In the NBD case, the scope creep was basically driven by the researchers since we realized that the progress for the customer would be much bigger when focusing on modeling organisational competences rather than staying on team level. The responsible persons at the customer not only understood and accepted the change, but also supported it actively, since it was in line with other developments in the organisation. The scope shift actually was not perceived as problematic for the project.

Our recommendation is to treat substantial changes in project objective or plans openly with the customer and as thoroughly as a project set-up.

\section{Project delay due to administrative overhead in the military domain}

In the list of domain-specific project risks, many textbooks include for military projects that administration overheads can cause delays. Unfortunately, the NBD project confirms this statement to some extent: it was not sufficient for the project owner to identify a suitable person in the military organisation with experience in team formation for military missions, the availability of this person also had to be checked and he had to be released from his duties in the chain of command. The situation would probably have been similar in industrial organisation with several departments. 
Table 1. Summary of problems in NBD project

\begin{tabular}{lcc}
\hline Problem experienced & $\begin{array}{c}\text { Original } \\
\text { contingency plan }\end{array}$ & Actual action \\
\hline $\begin{array}{l}\text { Key personnel not } \\
\text { available }\end{array}$ & $\begin{array}{c}\text { Staffing of the } \\
\text { project with two } \\
\text { persons for project- } \\
\text { critical tasks }\end{array}$ & $\begin{array}{c}\text { Problem occurred on } \\
\text { customer and } \\
\text { researcher side; } \\
\text { staffing not } \\
\text { performed as planned } \\
\text { Shift project }\end{array}$ \\
$\begin{array}{l}\text { Organisational changes } \\
\text { lead to turbulences in } \\
\text { project }\end{array}$ & $\begin{array}{c}\text { Establish support for } \\
\text { the project on top } \\
\text { level at the customer } \\
\text { side in order to have } \\
\text { fall-back level in } \\
\text { place }\end{array}$ & $\begin{array}{c}\text { ownership from two } \\
\text { to one of the partners }\end{array}$ \\
$\begin{array}{l}\text { Shift in scope } \\
\text { Establish change }\end{array}$ & $\begin{array}{c}\text { Re-plan project after } \\
\text { scope shift }\end{array}$ \\
$\begin{array}{c}\text { request procedure for } \\
\text { agreement on new } \\
\text { requests }\end{array}$ & \\
$\begin{array}{l}\text { Project delays due to } \\
\text { administrative overhead } \\
\text { in particular in military } \\
\text { projects }\end{array}$ & $\begin{array}{c}\text { Include time buffers } \\
\text { in project planning } \\
\text { for parts depending } \\
\text { on military partner }\end{array}$ & Time buffers were \\
& too small \\
&
\end{tabular}

Table 1 summarizes the problems that occurred, the original contingency plan, and the actual way to manage the situation.

\subsection{Challenges Originating from Innovative Modeling Projects}

In addition to the project risks introduced in section 4.1, we also collected experiences related to the nature of the modeling project. As described in section 3, the networkbased defence project was aiming at exploring innovative ways in competence supply, including new ways to model organisational competence demand and to capture team competences. The innovative character encompassed both, the modeling approach and the thinking and practice in the military domain. Capturing organizational competence demand with enterprise models in order to use this for information searching and team composition was new for the project team involved. Using enterprise modeling experiences as a basis created a good level of confidence that the project team would be able to deliver the expected results, but potential changes regarding modeling approach or required additional elements in the modeling notation were not known at the beginning.

For the military application area, the idea of functional teams representing a specific organizational competence "module" was far from common practice. On the strategic level, this idea was developed and to some extent already accepted, but in the organization in general, it was widely unknown.

This "double innovation" situation was a project risk as such, but this was realized only afterwards since the research side did not understand the conflict potential attached to the functional team idea, which probably was similar on the military side 
regarding low maturity of the competence modeling idea. On project management and steering board level, an agreement was made what modeling steps to use, how to follow-up and validate the results, and how to disseminate conclusions from the project. During the first follow-up session, when the problems regarding acceptance began to surface, the management level strongly recommended to continue the planned way of working because of the strategic value of the project.

At the end, both innovations survived the feasibility test, but both need additional evaluation. Our conclusion for future projects is to avoid to simultaneously have modeling innovation and domain innovation in a project, where domain innovation may not be well accepted at all organizational levels. Although, in general, modeling innovation and domain innovation can well co-exist together, in some projects it may lead to unnecessary complexity and decreased level of control. It is therefore advisable to first investigate if domain innovation is welcomed or at least accepted at different organizational levels. If it is not, these aspects should be investigated sequentially. Furthermore, we will spend more time on understanding the domain under consideration in situations where domain innovations are possible in order to better grasp the consequences of these innovations.

Another experience during the project, which created problems and is related to the innovation character of the project, was that the possibility that the project in the long run might lead to changes quite instantly created reluctance on the employee side to participate in project related activities. It is well-known that many organizational change projects fail due to missing acceptance of the employees or due to insufficient management support. But it was a new experience for the project team that only mentioning potential organizational innovations already created this reaction. More concrete, during the modeling session with the domain expert, the idea of training and forming smaller "functional" units which provide specific well-defined competences instead of conventional large units caused a long discussion about this issue. Afterwards, the actual modeling purpose was difficult to put back into focus and to complete the modeling exercise became a challenge.

\section{Conclusions}

In this paper we have discussed success and failure of a project concerned with enterprise modeling of network-based defence. The project aimed at creating concepts and methods for modeling competence demand within an organization. During the project runtime we encountered typical problems of project management as well as more specific difficulties originating from the innovative character of the modeling project.

The standard project management problems were lack of key personnel, organisational changes, shift in scope, and project delays. The actions taken were in line with usual project management recommendations. The lesson learned is that despite the fact that these are well-known project risks and we addressed them in contingency plans in the project, we could not completely eliminate the problems.

The challenges due to the innovative character of the project are more interesting. The problem was that innovations were required in the modeling approach as well as the thinking and practice in the military domain. The lesson learned is that it is better 
to avoid this kind of "double innovation" in a project if domain innovation is not well accepted at different organizational levels. In such a case, modeling innovation and domain innovation should be investigated sequentially. This will allow for higher level of control and decreased complexity. One more problem was that the project on the long run might lead to changes. The next lesson learned is that even possibility of potential organizational innovations can create negative reaction of the employees and reluctance to contribute to the project.

The case analysis and lessons learned presented in this paper are relevant for modeling projects in the military domain. However, we think that the results can be also applied to industrial organizations with several departments and busy key personnel.

\section{Acknowledgements}

Some parts of the research presented were financed by the Swedish Armed Forces with the project "Competence modeling and matching (KOMO)".

\section{References}

1. Bubenko, J., Persson, A., Stirna, J.: Proc. 1. IFIP working conference on the Practice of Enterprise Modeling, PoEM, Stockholm, Sweden. LNBIP, vol. 28. Springer, Heidelberg (November 2008)

2. Fox, M., Gruninger, M.: Enterprise Modeling. The AI Magazine, 109-121 (1998)

3. Madarász, L., Timko, M., Raček, M.: Enterprise modeling and its application in company management systems (2004)

4. Stirna, J., Persson, A. (eds.): Proc. 2. IFIP working conference of the Practice of Enterprise Modeling, PoEM, Stockholm, Sweden. LNBIP, vol. 39. Springer, Heidelberg (November 2009)

5. Wordnet (2010), http: / /wordnetweb.princeton.edu/perl/webwn?s=enterprise

6. Wolverton, M.: Exploiting enterprise models for the automatic distribution of corporate information. In: Proceedings of the Sixth international Conference on information and Knowledge Management, CIKM 1997, Las Vegas, Nevada, United States, November 10-14, pp. 341-347. ACM, New York (1997)

7. Presley, A., Huff, B., Liles, D.: A Comprehensive Enterprise Model for Small Manufacturers. In: Proceedings of the Second Annual Industrial Engineering Research Conference. Los Angeles, CA (1993) 